\title{
Prototype Perancangan dan Implementasi Alat Perontok dan Pengering Padi Otomatis dengan Konsep Teknologi Pembangkit Listrik Tenaga Surya untuk Meningkatkan Produktivitas Hasil Pertanian
}

\author{
Prototype of Design and Implementation of \\ Automatic Rice Thresher and Dryer with the \\ Concept of Solar Power Generation Technology \\ to Increase Agricultural Productivity
}

\author{
Meiyanto Eko Sulistyo ${ }^{*}$, Chico Hermanu Brillianto Apribowo ${ }^{2}$, Feri Adriyanto ${ }^{3}$ \\ 1,2,3 Teknik Elektro, Fakultas Teknik, Universitas Sebelas Maret \\ mekosulistyo@staff.uns.ac.id ${ }^{1 *}$, chico@ft.uns.ac.id ${ }^{2}$, feri.adriyanto@staff.uns.ac.id ${ }^{3}$
}

\begin{abstract}
Abstrak - Dewasa ini pemanfaatan teknologi untuk meningkatkan hasil pertanian tumbuh pesat. Salah satu bentuk pemanfaatannya adalah dengan menggunakan energi terbarukan untuk meningkatkan produktivitas hasil pertanian. Energi terbarukan yang implementasinya sudah sangat banyak adalah Pembangkit Listrik Tenaga Surya (PLTS). Pengunaan PLTS sebagai sumber energi alternatif yang digunakan untuk pengerak alat perontok dan pengering padi otomatis. Petani selalu kesulitan saat musim penghujan maupun kemarau kering tiba-tiba dan sinar matahari tidak dapat mencapai intensitas maksimal saat digunakan untuk mengeringkan padi secara konvensional, oleh karena itu alat perontok dan pengeringan padi otomatis tenaga PLTS sebagai alternatif solusi. Tujuan penelitian ini adalah untuk memberi wawasan dan pengetahuan akan pembuatan dan prinsip kerja dari alat perontok dan pengeringan padi otomatis tenaga PLTS sebagai alternatif solusi untuk meningkatkan padi secara teknologi, dengan demikian diharapkan masyarakat mendapatkan manfaat lebih cepat dalam pengeringan padi dan menghemat biaya untuk pengeluaran memanen padi, sehingga dapat meningkatkan produktivitas hasil pertanian.
\end{abstract}

Kata Kunci: Perontok, pengering, energi terbarukan, PLTS.

\begin{abstract}
Nowadays the use of technology to increase agricultural output is growing rapidly. One form of utilization is to use renewable energy to increase the productivity of agricultural products. The renewable energy that has been implemented very much is the Solar Power Plant (PLTS). The use of PV mini-grid as an alternative energy source, which is used for automatic threshing machines and rice dryers. Farmers always have difficulty during the rainy season or wet dry season and sunlight cannot reach the maximum intensity when it is used to dry rice conventionally, therefore an automatic thresher and rice dryer with PLTS power is an alternative solution. The purpose of this research is to provide practical insight and knowledge on the manufacture and working principles of automatic PLTS-powered rice thresher and dryer as an alternative solution for drying rice technologically, thus it is hoped that the community will benefit in the form of faster drying of rice and saving in expenses. costs to harvest rice, so as to increase the productivity of agricultural products.
\end{abstract}

Keywords: thresher, dryer, renewable energy, PLTS.

Jurnal Bumigora Information Technology (BITe)

Vol.3, No.1, Juni 2021, pp. 38-44

ISSN: $2685-4066$

DOI: $10.30812 /$ bite.v3i1 


\section{Pendahuluan}

Saat ini Indonesia mengalami anomali akan ketahanan pangan. Hal ini diindikasikan oleh peningkatan impor beras Indonesia yang semula pada tahun 2017 sebesar 305.274,5 ton atau senilai 143.641,7 US\$ menjadi sebesar 2.253.824,5 atau senilai 1.037.128,4 US\$ ditahun 2018[1]. Kenaikan impor beras yang cukup signifikan ini merupakan indikator bahwa produksi domestik beras di Indonesia mengalami pernurunan. Penurunan produksi domestik beras ini diakibatkan oleh banyak faktor berantai salah satunya adalah Petani selalu kesulitan saat musim penghujan maupun kemarau basah tiba dan sinar matahari tidak dapat mencapai intensitas yang maksimal saat digunakan untuk proses mengeringkan padi secara konvensional. Proses pengeringan yang masih mengunakan cara konvensional dan kurang optimal inilah salah satu penyebab turunnya hasil pertanian. Sehingga dibutuhkan suatu solusi teknologi tepat guna berupa alat perontok dan pengering padi otomatis yang bisa digunakan tanpa terpengaruh oleh kondisi cuaca nantinya dapat meningkatkan produktivitas hasil pertanian petani.

Seiring dengan kemajuan teknologi dan ilmu pengetahuan telah banyak ditemukan sumber energi terbarukan sebagai penganti bahan bakar minyak. Salah satunya adalah pemanfaatan teknologi Pembangkit Listrik Tenaga Surya (PLTS)[2][3] yang digunakan untuk sumber energi pengerak. Pemanfaatan PLTS sebagai sumber energi alternatif sudah semakin meningkat dari tahun ke tahun khususnya di negara Indonesia, dari pemanfaaatan PLTS untuk sumber energi skala kecil hingga skala besar, mulai dari sumber energi cadangan pada rambu-rambu lalulintas, untuk sumber energi pada kendaraan, pemanfaatan bidang pertanian, dan dll. Hal ini juga didukung dengan besarnya Radiasi matahari di negara Indonesia nilainya relatif tinggi yaitu rata-rata sebesar $4,5 \mathrm{kWh} / \mathrm{m}^{2} / \mathrm{hari}$ [4]. Selain itu pengunaan Sistem Pengering Tenaga Surya Menggunakan Tipe Greenhouse dengan Kotak Kaca[5], [6] yang produksi pengeringan padinya masih bergantung pada intensitas sinar matahari. Pontensi inilah pengunaan PLTS digunakan untuk memodifikasi mekanisasi pengering padi yang semula mengunakan blower listrik PLN maupun yang konvensional, dengan mengunakan Sistem perontok dan pengering Tenaga Surya menggunakan Tipe Greenhouse dengan Kotak Kaca dan blower yang diharapkan dapat memberikan alternatif solusi yang murah dan ramah lingkungan. Sehingga implementasi alat perontok dan pengering padi otomatis PLTS ini memiliki potensi yang sangat menjanjikan.

Pemanfaatan sistem PLTS sebagai sumber energi listrik telah mengalami peningkatan dari tahun ke tahun. Pada mega proyek pembangkit 35.000 MW setidaknya ada alokasi $10 \%$ pembangkit energi baru dan terbarukan yang dibangun oleh pemerintah[7]. Hal ini tentunya membawa angin segar bagi pengiat pembangkit EBT terutama PLTS. Implementasi PLTS telah diterapkan diberbagai bidang tak terkecuali bidang pertanian.

Implementasi PLTS di bidang pertanian yang lain digunakan sebagai pengerak Pompa Air Tenaga Surya[8]. Pompa Air Tenaga Surya dengan daya 200 Watt dapat berjalan dan digunakan oleh petani. Kemudian sistem PLTS juga dimanfaatkan untuk pemantau air bersih[9] yang dapat dikontrol mengunakan smartphone.

Dari inovasi penelitian dan penelitian sebelumnya sistem PLTS ini perlu dikembangkan sebagai sumber energi penggerak motor perontok padi dan blower pengering padi agar memiliki multi fungsi yang lebih bagi petani.

\section{Metode Penelitian}

Dalam penelitian ini akan dibahas metode perancangan, pembuatan, dan implementasi sistem pengering dan perontok padi. Tahap awal terdiri dari Pengumpulan bahan-bahan referensi, studi literatur dan pengumpulan data. Tahap kedua perancangan dan simulasi sistem. Tahap ketiga pembuatan hardware dan program beserta uji coba. Tahap keempat pemasangan, implementasi, dan pengujian. Tahap kelima Analisa Data, Pelaporan, dan Evaluasi.

https://journal.universitasbumigora.ac.id/index.php/bite

ISSN: 2685-4066 


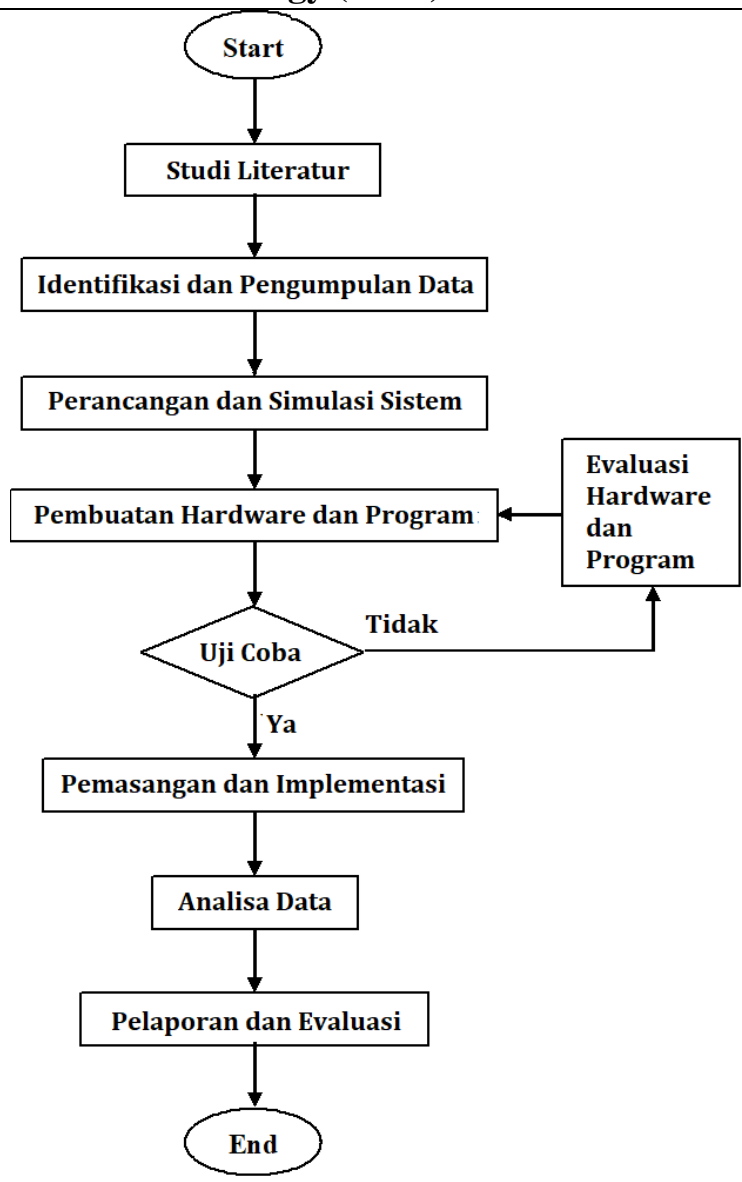

Gambar 1 Diagram alir penelitian.

\subsection{Studi Literatur}

Pada tahapan awal ini mengumpulkan data-data referensi yang dibutuhkan berupa artikelartikel terkait (paper atau jurnal), buku, dan informasi lainnya yang membahas dan meneliti tentang:

1.Sistem PLTS,

2.Jenis dan spesifikasi blower dan elemen pemanas

3.Perancangan dan pembuatan sistem pengerak dan pengayak

4.Spesifikasi lemari dan sensor kelembaban yang digunakan

\subsection{Identifikasi dan Pengumpulan Data}

Pada tahap ini dilakukan survei untuk mengidentifikasi permasalahan dan menghimpun data di lapangan (di daerah penelitian, desa Karangjoho) data yang dihimpun meliputi:

a. Luas lahan pertanian

b. Total hasil panen petani desa karangjoho baik per masa tanam atau total

c. Kebutuhan luas lahan pengeringan padi

d. Waktu bercocok tanam sampai dengan panen

\subsection{Perancangan dan Simulasi Sistem}

Tahapan ini berupa peracangan sistem dan simulasi perontok dan pengering padi otomatis tenaga PLTS mengunakan simulasi terlebih dahulu. Membuat model perancangan yang lebih 
optimal dibandingkan peralatan yang sudah ada di pasaran berdasarkan studi literatur dan pengumpulan data sebelumnnya. Membuat model perancangan yang lebih optimal perontok dan pengering padi otomatis baik dari segi material, desain dan sistem programmnya. Sehingga dihasilkan produk yang siap digunakan oleh masyarakat.

\subsection{Perancangan Hardware dan Software}

Dalam pembuatan hardware dan program produk perontok dan pengering padi otomatis tenaga PLTS ini menggunakan sensor DHT-11 berbasis mikrokontroler tersusun dari beberapa blok diagram diantaranya, rangkaian catu daya, sistem minimum mikrokontroler, penampil LCD, sensor DHT11, blower dan heater [10]. Adapun bentuk susunan sistem secara keseluruhan ditunjukkan pada Gambar 2.

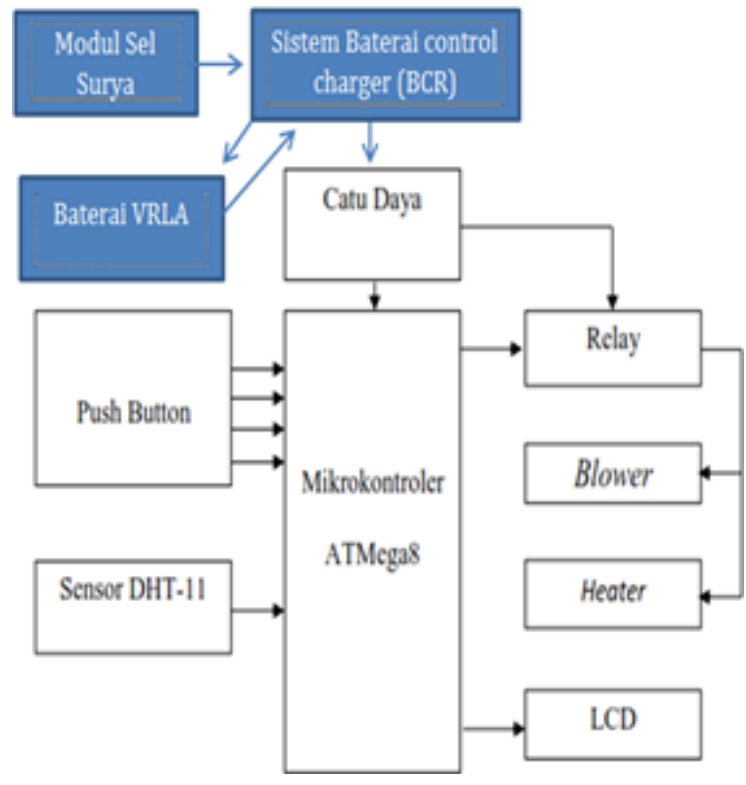

Gambar 2 Blok rancangan sistem.

\subsection{Pemasangan dan Implementasi}

Apabila inovasi produk pengering padi tenaga PLTS ini sudah teruji skala lab kemudian pada tahap ini dilakukan pemasangan dan implementasi di daerah penelitian. Perlu adanya penyuluhan berupa cara mengunakan alat, cara kerja alat dan perawatan inovasi pengering padi otomatis tenaga PLTS.

\subsection{Analisis Data dan Pelaporan}

Pada tahap ini dilakukan monitoring dan analisa data, untuk dianalisa proses sebelum dan sesudah dipasang peralatan pengering padi otomatis tenaga PLTS. Kemudian tahapan terakhir pelaporan dan evaluasi kegiatan penelitian ini secara keseluruhan.

\subsection{Peran dan Tugas Institusi Mitra}

Peran dari mitra dalam ini membantu penyuluhan dan membatu memberikan informasi keadaan real di lapangan serta beberapa permasalahan yang dihadapi masyarakat di Desa Karangjoho. Disamping itu mitra dilibatkan penyuluhan berupa cara mengunakan alat, cara kerja alat dan perawatan pengering padi tenaga PLTS. Tugas dari mitra membatu memfasilitasi tempat sosialisasi dan penyuluhan produk pengering padi otomatis tenaga PLTS. Merawat dan menjaga produk alat pengering padi otomatis tenaga PLTS. 


\section{Hasil dan Pembahasan}

\subsection{Kondisi Eksisting Tempat Penelitian}

Mata pencaharian utama penduduk desa Karangjoho adalah Petani, dengan total luas lahan pertaniannya kurang lebih sebesar 25 HA. Petani di desa Karangjoho memanfaatkan Sungai Dekeng, (anak Sungai Begawan Solo) sebagai sumber utama irigasi lahan pertanian. Sejak 10 tahun terakhir petani di Desa Karangjoho selalu dihadapkan dengan bebagai permasalahan yang menghambat produktivitas pertanian. Secara umum ada beberapa permasalah utama yang dihadapi petani Desa Karangjoho :

1. Penggunaan diesel/pompa air dengan BBM yang mahal

2. Hama wereng yang secara sistemik dan periodik menyerang tanaman padi

3. Hama Tikus

4. Kondisi Daun Gading atau daun berwarna kuning tanaman padi

5. Tingkat kesuburan tanah yang kurang

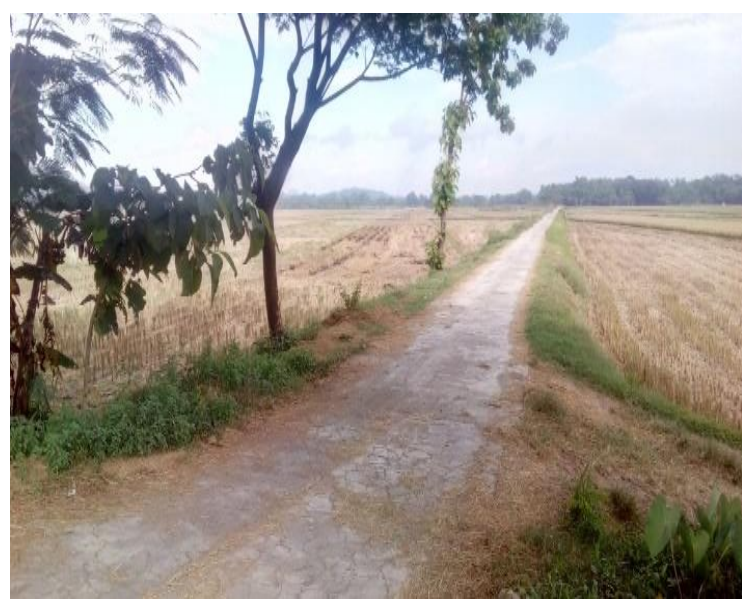

Gambar 3 Kondisi tempat penelitian.

\subsection{Pembuatan Prototipe Pengering}

Berikut perhitungan perancangan :

1. Beban yang disuplai 48-100 Volt 120 Watt. Dengan asumsi menyala selama 5 Jam/Hari

2. Total daya per hari $=120$ Watt $\times 5 \mathrm{Jam}=600 \mathrm{Wattjam}(\mathrm{Wh})$

3. Perhitungan panel surya beban total/kapasitas 1 panel surya $=600 \mathrm{Wh} / 150 \mathrm{Wp}=4$ buah panel

4. Total Daya $=150 \mathrm{Wp} \times 5 \mathrm{Jam}=750 \mathrm{Wh}$

5. Perhitungan Inverter

Untuk sistem yang berdiri sendiri, inverter harus cukup besar untuk menangani jumlah Watt yang akan gunakan pada satu waktu. Ukuran inverter harus $25-30 \%$ lebih besar dari total watt peralatan. Dalam hal tipe alat adalah motor atau kompresor maka ukuran inverter minimal 3 kali kapasitas peralatan tersebut dan harus ditambahkan ke kapasitas inverter untuk menangani arus gelombang saat memulai.

Total kapasistas inverter $=3 \times 120 \mathrm{Watt}=360 \mathrm{Watt}$ 


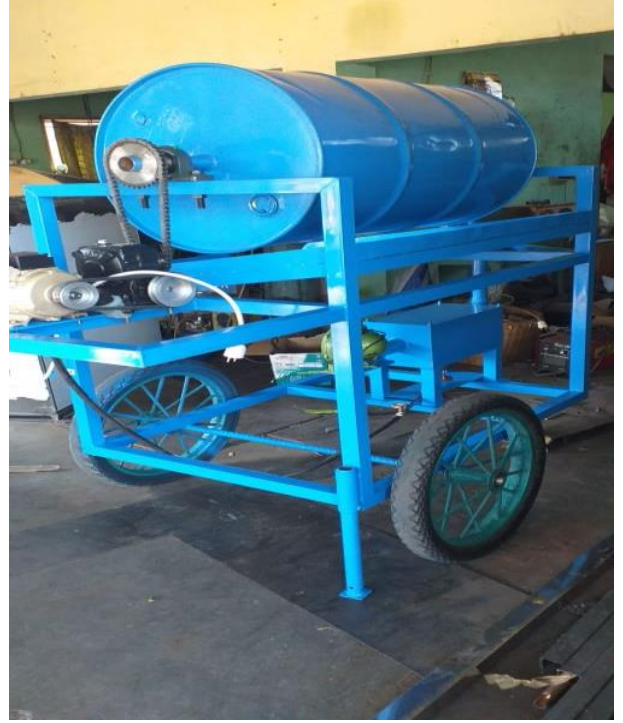

Gambar 4 Prototype awal pengering.

\section{Kesimpulan}

Dari kegiatan yang telah dilakukan dapat disimpulkan bahwa, hasil survei dilapangan untuk menentukan spesifikasi dari sistem PLTS dibutuhkan data beban, jam nyala beban harian, kapasitas panel surya, dan kedalaman irigasi yang dibutuhkan. Kemudian prototype sistem pengering perlu dikembangkan lagi agar memenuhi proses produksi. Dibutuhkan sistem proteksi tambahan agar sistem kontrol aman dari gangguan hubung singkat.

Penggunaan teknologi tepat guna harus dapat diterapkan lebih luas lagi, terutama penggunaan teknologi berbasis energi terbarukan, hal ini berguna untuk meningkatkan efektivitas dan efisiensi sistem yang ada.

\section{Ucapan Terima Kasih}

Penulis mengucapkan terima kasih kepada Kelompok Tani Sedyo Mulyo dan Pemerintah Desa Karangjoho, Klaten, Jawa Tengah yang telah melakukan penelitian ini.

\section{Referensi}

[1] BPS, "Statistika Indonesia 2019," Badan Pusat Satistik Indonesia, 2019. https://www.bps.go.id/publication/2019/07/04/daac1ba18cae1e90706ee58a/statistikindonesia-2019.html.

[2] I. Rahardjo and I. Fitriana, "Analisis Potensi Pembangkit Listrik Tenaga Surya," no. March, pp. 43-52, 2005.

[3] I. N. S. Kumara, "Pembangkit Listrik Tenaga Surya Skala Rumah Tangga Urban Dan Ketersediaannya Di Indonesia," Majalah Ilmiah Teknologi Elektro, vol. 9, no. 1, 2010.

[4] M. Bachtiar, "Procedures for designing a solar home system," Jurnal SMARTek, vol. 4, no. 3, pp. 176-182, 2006, [Online]. Available:

https://media.neliti.com/media/publications/221906-prosedur-perancangan-sistempembangkit-l.pdf.

[5] I. F. Putri, R. Hantoro, and D. D. Risanti, "Studi Eksperimental Sistem Pengering Tenaga Surya Menggunakan Tipe Greenhouse Dengan Kotak Kaca," Jurnal Teknik ITS, vol. 2, no. 2, pp. B310-B315, 2013, [Online]. Available:

http://www.ejurnal.its.ac.id/index.php/teknik/article/view/4290. 
[6] R. D. . Yayiendra.N.F., Hantoro.R., "Studi Eksperimental Sistem PengeringTenaga Matahari Tipe Rumah Kaca dengan Variasi Jarak Cermin dalam Pengeringan," Jurnal Teknik POMITS, vol. 2, no. 2, pp. 176-181, 2013.

[7] I. Jonan, "Rencana Usaha Penyedia Tenaga Listrik PT Perusahaan Listrik Negara (Persero) Tahun 2017 s.d. 2026," Kementerian Energi dan Sumber Daya Mineral, 2017. https://web.pln.co.id/statics/uploads/2017/12/RUPTL-PLN-2017-2026.pdf.

[8] C. Hermanu, B. Apribowo, T. E. S, and M. Anwar, "Prototype Sistem Pompa Air Tenaga Surya Untuk Meningkatkan Produktivitas Hasil Pertanian," Jurnal Abdimas, vol. 21, no. 2, pp. 97-102, 2017.

[9] R. Rachmatika and F. Adriyanto, "Development of realtime, handheld and portable flood distribution and water quality sensor based android smartphone," AIP Conference Proceedings, vol. 1883, no. September, 2017, doi: 10.1063/1.5002038.

[10] M. Ardi and H. Amri, "Analisa Rancang Bangun Alat Pengering Pakaian Otomatis," JEECAE (Journal of Electrical, Electronics, Control, and Automotive Engineering), vol. 4, no. 1, pp. 253-256, 2019, doi: 10.32486/jeecae.v4i1.326. 